\title{
Fintech as a transformation driver of global financial markets
}

\author{
Natalia Serbulova ${ }^{1 *}$ \\ ${ }^{1}$ Don State Technical University, 1 Gagarin sq., Rostov-on-Don, 344003, Russia
}

\begin{abstract}
Information technology is a driving innovation in the financial industry now. Fintech is a disruptive innovation capable of changing traditional financial markets. Although the fintech has been widely discussed, there is a lack of consensus on the definition of the term in the scientific literature. This article investigates the concept of fintech, discusses the emergence and development of fintech sector, and points out new routes and trends in the field of study. This research focuses on the next generation technologies impact on fintech, key drivers and challenges in the global fintech industry. The research represents the current most sensitive aspects also linked to the more global theme of digital transformation. Finally, subject related to the fintech infrastructure in Russia is performed. From practical aspect, this paper is also a direction for companies to help them find out promising technology in fintech. The paper can inspire future research on fintech and its application in the business world.
\end{abstract}

\section{Introduction}

Today, new technologies (digital, telecommunications, biometrics, etc.) are reshaping financial services industry, actively displacing traditional players and traditional business models. Integration of new financial solutions makes it possible to change consumption patterns, reduce costs for certain functionality (processing of customer bases, loyalty programs, etc.), improve efficiency and business processes quality (audience targeting, scoring, etc.), and significantly influence sustainability of core business development. As a result, the financial technology industry (fintech) is transforming itself into intensively developing sector of the modern economy [1-2].

Gradually, various kinds of innovative fintech business models appear in financial market. Fintech business model is the specific application of fintech in the economic and financial fields. For example, e-banking integrates internet technology, APP and mobile payment. It enables users to complete bank account transaction at home, which improves the efficiency of bank transactions and saves customers' time [3]. Ongoing shifts toward ecommerce, digital payments (including contactless), instant payments, and cash displacement have all been significantly boosted in 2020 .

\footnotetext{
*Corresponding author: nserbulova@mail.ru
} 
Lee and Shin [4] identified six fintech business models, including payment business model, wealth management business model, crowdfunding business model, lending business model, capital market business model and insurance services business model.

The World Economic Forum defines fintechs as «companies that provide or facilitate financial services by using technology. In its current form, fintech is marked by technology companies that disintermediate formal financial institutions and provide direct products and services to end users, often through online and mobile channels» [5]. Another definition for fintech by $\mathrm{PwC}$ is «a dynamic segment at the intersection of the financial services and technology sectors where technology-focused start-ups and new market entrants innovate the products and services currently provided by the traditional financial services industry. As such, fintech is gaining significant momentum and causing disruption to the traditional value chain» [6].

The financial technology sector is a new and rapidly developing industry that has emerged at the intersection of the financial services and new technologies sectors. Its participants create user-oriented innovative solutions for the multi-segment financial services market. These are segments such as retail and corporate banking, insurance, brokerage and others. However, the key players are predominantly technology companies rather than traditional financial sector players. Fintech projects integrate innovations faster than classical financial institutions, add new products and services faster, change business models and are ready to provide services in almost all market segments [7]. Traditional players, on the other hand, have to adapt their products to a new reality or develop new ones. Today, competition between technology companies and financial institutions is growing.

\section{Emergence and development of fintech}

The rise of fintech began in 2008, when the global financial crisis forced financial companies to cut costs, and is closely linked to other notable subsectors like Cybersecurity and the rapidly growing Blockchain subsector [8]. Huge financial institutions all over the world have taken the biggest hit from both economic and public trust perspectives. Crisis environment and low public trust of big companies opened the door for a new kind of financial institutions. An alternative to current financial institutions came into the picture with small, controllable, and transparent features.

This coincided with a boom in mobile technology, which continues today. Mobile devices are used by $66.6 \%$ of the world's population. Portable gadgets (smartphones, tablets, smart watches, etc.) have made it possible for people to be in cyberspace $24 / 7$, where commerce, education, communication, entertainment, work processes, etc. are gradually moving. Over the last 5 years, the daily time spent online has increased by an average of half an hour: in 2015, people spent 6 hours and 20 minutes online every day; by the end of 2020, this figure was already close to 7 hours. These processes became even more intense during the COVID 19 pandemic [9]. Accordingly, new living conditions require new ways of dealing with finances [10]. Thus, emerging fintech companies based on disruptive technologies (big data analytics, artificial intelligence, distributed registry technologies, biometrics, etc.) are successfully filling this niche. Such organizations, as global practice shows, are more responsive to market changes than traditional financial institutions, and add completely new products and services faster. The target audience of such start-ups is the new generations of consumers who have grown up with digital technologies.

The global financial technology market is one of the fastest growing in the world. According to expert estimates, the number of financial technology users in the world is growing annually by $15-20 \%$, which is actively supported by the growth of Internet users 
number in the world (4.72 billion people in April 2021). The Internet is used by almost $60 \%$ of the world's population, with the number of users increasing by $7.3 \%$ over the year. Figure 1 presents overview of global Internet use in key regions in April 2021 (data source: We are Social, Hootsuite).

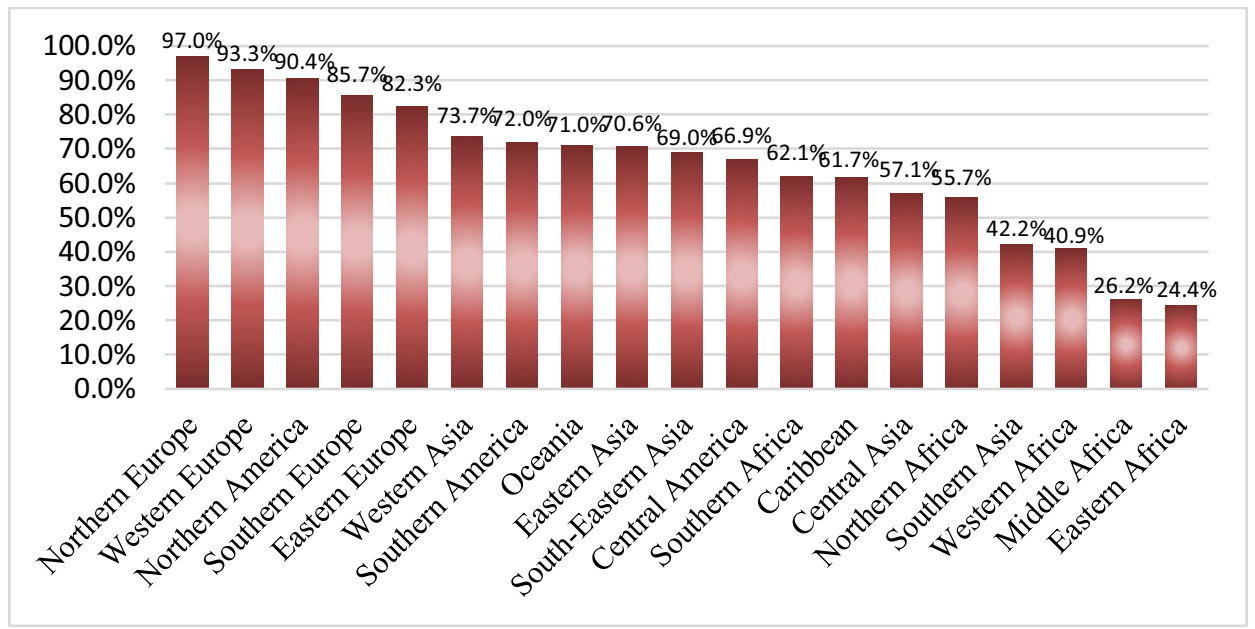

Fig. 1. Overview of global Internet use, April 2021.

According to Pulse of Fintech, global investment in fintech ventures reached US \$105 billion in 2020. Much of this increase in investment has come from traditional financial institutions. Traditional financial institutions invest in external fintech start-ups in the form of collaborative fintech ventures, as well as their internal fintech projects in hopes of leapfrogging fintech innovation and gaining a competitive advantage.

On a country-by-country basis, the US and the UK are considered the most mature markets. However, other regions, particularly Asia Pacific (investments in Australia almost tripled to US $\$ 1.2$ billion, making the country the world's fourth largest fintech market, while fundraising in Japan quadrupled to US\$268 million and jumped 65\% in South Korea to US\$162 million), are focused on building their own mature fintech industries. Investment in fintech ventures edged higher in the first half of 2020, led by strong gains in China, Australia and the UK that helped more than offset a drop in fundraising in the US (the world's largest fintech market, fell $9.1 \%$, to US\$11.6 billion) and some European markets.

It is worth noting the heterogeneous composition of the new industry. Surely, fintech start-ups are the driving force, but traditional financial institutions are also actively investing in modern technology, so as not to leave innovative companies any room to manoeuvre and strengthen their positions. Financial institutions are now competing with large Internet corporations, telecommunications companies, retailers, carmakers, electronics manufacturers and some other non-financial players, i.e. those with large customer bases.

The impact of the fintech industry on global financial markets is also worth highlighting. New technologies implementation increases competition in financial markets [11]. Product offerings are expanding and becoming more personalized, while access to products is becoming easier. The lines between lifestyle financial products and services are gradually blurring, defining new standards. New flexible business models are emerging and evolving, enabling them to operate in new market niches. P2P services, for example, have become the most important form of new relationships created by the fintech industry development [12]. 
New solutions help significantly reduce the cost of attracting and servicing clients, assess and prevent existing and new risks, find new sources of income, etc. At the same time business transparency is increasing. Distributed systems gradually restructure existing business models, making them as transparent as possible. Big data analytics enables financial companies to identify new categories of potential customers, develop targeted offers, and improve customer service, thereby increasing their loyalty.

In addition, financial supervision is being transformed. It is often the case that new technological financial products/services/business models are outside the existing legal framework. Regulatory authorities are exploring technology deployment and working with traditional and new players to develop effective regulations [13]. Global regulators have realized that deployment of the necessary infrastructure (e.g. open banking, biometric systems, etc.) is necessary for long-term sustainable growth of the financial sector.

\section{Technologies impact on the financial market}

Today's financial market is influenced by the next generation of technologies that are directly linked to the Internet [14]. Examples of such technologies include:

- Mobile technology - a set of mobile devices and applications that are based on wireless communication. Mobile communications infrastructure is developing at a rapid pace. The geographical reach of the mobile Internet is expanding and its speed is increasing. This has been accompanied by the mobile device market accelerating development (smartphones, smart watches, smart rings, etc.). In the financial sector, the mobile technology development has led to the emergence of mobile banking, which involves managing a bank account via mobile devices such as smartphones, tablets, smart watches, etc. Normally, a special app needs to be downloaded onto a mobile device. In addition, players are developing special mobile devices to make it easier to obtain financial services and increase the loyalty of the target audience (payment smart rings, key rings, bracelets, physical plastic card aggregators, etc.).

- Big data - designation of structured and unstructured huge volumes of data, as well as technologies of their processing and use, methods of searching for necessary information in large arrays. The sources of data are various Internet documents, social networks, bank card transactions, radio-frequency identification, audio and video recording devices, etc. Big data analytics enables financial institutions to identify new consumer categories, create personalized products, etc.

- Artificial intelligence (AI) - technologies enabling the creation of intelligent machines and programmes capable of performing creative functions that are traditionally considered to be the human prerogative (e.g. writing music, literary works, etc.). AI-based technologies allow financial companies to be proactive and provide the most personalized service possible while reducing costs.

- Digital currency technologies. Digital currencies are non-tangible currencies that can be used by both individuals and legal entities as full-fledged monetary units. To use digital currencies, it is not necessary to open an account at a traditional bank; an online registration with the relevant payment system is sufficient. Today, there are two types of digital currencies - electronic wallets (e.g. PayPal, WebMoney, ApplePay, etc.) and cryptocurrencies (bitcoin, etherium, lightcoin, etc.). But while electronic wallets need to be funded with «traditional» money, the issuance (mining), exchange and accounting of cryptocurrencies is based on the specific application of cryptographic algorithms (encryption). All cryptocurrencies are based on blockchain (or distributed ledger technology) - a chain of information blocks arranged in a strict sequence and according to certain rules. Each record contains information about the history of ownership, making it extremely difficult to falsify information. Blockchain-based fintech projects are growing 
rapidly around the world [15]. Some countries have already recognized cryptocurrencies as a full-fledged means of payment and have even begun to develop their own national cryptocurrency (e.g., Venezuela, Estonia, UAE). Other states have restricted the use of cryptocurrencies or banned them altogether, seeing them as a threat - depriving the state of its exclusive right to issue currency (e.g. China, India, Nigeria, Bolivia).

- Virtual reality and augmented reality. Virtual reality is computer-generated environment. that can be explored and interacted with by a person. In order to create a convincing set of sensations, computer synthesis of virtual reality properties and reactions is realized in real time. Augmented or mixed reality is actually the augmentation of the real existing physical world with digital and graphic data in real time using computerized devices. Traditional financial organizations and fintech start-ups are actively using virtual and augmented reality technologies to improve the quality of remote service and increase customer loyalty. For example, opening fully functional virtual branches, creating financial literacy training services, organizing virtual entertainment venues for their clients, etc.

- Contactless technologies are wireless short-range technologies operating at a distance of no more than $10 \mathrm{~cm}$. Information from objects is read via a radio signal. Today, they are integrated into smartphones, tablets, smart watches, plastic cards, etc. In the financial sector, contactless payments are made using devices usually with a built-in NFC chip smartphones, wristbands, etc.

- Biometric technology is based on biometrics, the measurement of an individual's unique characteristics. These are dynamic (behavioural) and static (physiological) characteristics. Behavioural features include voice, gestures and so on. Physiological features include fingerprints, facial geometry, eye's retina, etc. In fintech, biometrics is used in identification and authentication systems to improve the security of transactions.

Nowadays, the global market of technology solutions for the financial sector is one of the fastest growing. This means that projects that seemed utterly fantastic yesterday may already be in the final testing phase or even be put into operation today. Key drivers and challenges in the global fintech industry are shown in the Table 1.

Table 1. Key drivers and challenges in the global fintech industry.

\begin{tabular}{|l|l|}
\hline \multicolumn{1}{|c|}{ Drivers } & \multicolumn{1}{c|}{ Challenges } \\
\hline - A well-developed digital and & - Underdeveloped or unevenly developed digital \\
«traditional» financial infrastructure that & and financial infrastructure; \\
makes it easy to implement innovative & - Shortage of qualified personnel; \\
projects; & - Low level of technological and financial literacy \\
- Availability of qualified and creative & of the population; \\
personnel capable of generating new & - Low level of public trust in financial technologies. \\
solutions. Availability of favourable & Tendency towards conservative formats of financial \\
conditions for «brain gain» from other & services; \\
countries; & - Growth of cyber-threats and active fight against \\
- Loyalty of users (individuals and & cyber-criminals; \\
companies) to «non-traditional» financial & - Lack of market transparency, resulting in high \\
services, including cornerstone unbanked & risks for local and foreign investors; \\
and underbanked segments; & - Lack of responsive regulatory improvement in \\
- High investor interest in innovative & financial technology; \\
fintech projects; & - Without a proper portfolio management of fintech \\
- Effective government regulation & projects, financial firms can get easily swamped in \\
conducive to the fintech projects & the plethora of fintech technologies; \\
development. & - Technology integration is essential in providing \\
& seamless customer service. Many fintechs are based \\
on new technologies, and it is challenging to \\
integrate the fintech applications with existing \\
legacy systems.
\end{tabular}


Although the fintech market is in its infancy, a number of distinct niches, often interlinked with each other, can already be identified. The following are considered to be the most developed areas in the world today: alternative lending, payments and remittances (and related infrastructure), asset management and retail banking.

\section{Venture capital}

Venture capital is the main source of funding for fintech projects around the world, with its share in the total volume of financing accounting for over $70 \%$, according to McKinsey estimates. In addition, such traditional tools of capital raising as mergers and acquisitions, as well as direct investments and alternative ones, such as crowdfunding, P2B lending, and online factoring can be distinguished. The focus of international venture capitalists, including Silicon Valley legends, indicates a high appraisal of the prospects of fintech startups. This was true before the COVID-19 pandemic; after its first year, the trend has only intensified. KPMG estimates that fintech start-ups will raise over $\$ 105.3$ billion from private investors globally in 2020, based on 2,861 deals. Though during pandemic fintech investment dropped from $\$ 168$ billion in 2019 to $\$ 105$ billion in 2020, in part due to the lack of mega M\&A deals.

Investors have continued to show increased demand for mature companies. Recognized leaders in the new generation of financial services, Robinhood, Klarna, Stripe, Revolut and many others received the largest investments last year. Experts note the same trend as in the whole venture industry in recent years: there are more and more big checks, while earlystage startups are experiencing a shortage of funding. This means an increase in the overall volume of investment amid a decline in the number of deals.

London-headquartered business platform Checkout.com became Europe's most expensive fintech startup after a $\$ 450$ million round at a valuation of $\$ 15$ billion and the 4 th most capitalized non-public company in the world. In doing so, the company has almost tripled its valuation in just over six months, reflecting the impact of the pandemic on demand for remote financial services and how investors view the trend. Checkout.com provides companies with online payment acceptance, analytics and anti-fraud services.

Venture capitalists and private equity funds are investing in order to capture their return on the value of the asset at the exit of the investment at the time of the IPO or M\&A (merger and acquisition) transaction. The large number of late-stage, highly capitalized fintech companies suggests that an impressive overhang of potential fintech-IPOs has been created over the stock market. Meanwhile, companies of relatively small size but with currently relevant financial solutions are active in the public market. At the beginning of the year 2021, a successful IPO was conducted by Affirm, a fintech company that offers private customers online purchases in instalments at the point of sale (POS). After the flotation, it doubled in price and has a current market capitalization of $\$ 27$ billion. Now Affirm works with around 6,500 retailers, including well-known brands such as Walmart, Peloton, Wayfair, with next-generation start-ups Warby Parker and Casper Sleep, and has partnered with Shopify to enable the platform's merchants to offer instalment payments to customers at the POS. The service has been used by more than 6 million shoppers. The company aims to be a convenient alternative to credit cards. Fintech companies that went public earlier have reflected investor demand in share prices. The capitalization of PayPal and Adyen more than doubled during the year (at the end of January) to $\$ 315$ billion and $\$ 58$ billion respectively, and payment service Square rose almost 3 times to $\$ 105$ billion.

Based on the dynamics of investment activity, it can be noted that experts appreciate both the payment and business direction of fintech projects and the prospects of digital banks and individual banking services that solve problems of inconvenience and lagging behind the consumption trends of traditional market players. 


\section{Fintech industry infrastructure in Russia}

Today we are witnessing a global transformation of the existing technological structure and a transition to Industry 4.0 and the digital economy. According to global researchers, the technological foundation of the digital economy and, consequently, the fintech industry as an important component of the new economic model will be a number of conditionally basic end-to-end technologies: telecommunications technologies, big data analysis technologies, Internet of Things, Industrial Internet and artificial intelligence. Also interdisciplinary technologies include neurotechnologies, distributed registry systems, quantum technologies, new production technologies, robotics and sensorics components, virtual and augmented reality technologies. Many fintech start-ups are developing interesting conceptual solutions from various points of view, which cannot be scaled and replicated at the current level of infrastructure development.

Mobile technology has already seriously changed people's daily lives. At the same time, the technology itself is evolving at an enormous speed. More than $30 \%$ of the world's countries now have 5G availability. The GSM Association of Mobile Network Operators predicts that $5 \mathrm{G}$ networks will account for $15 \%$ of global connections by 2025 . And $5 \mathrm{G}$ adoption will add $\$ 2.2$ trillion to the global economy over the next 15 years. The most popular use cases for $5 \mathrm{G}$ services are expected to be extended mobile broadband with highspeed internet access, fixed wireless access and massive IoT connections with new capabilities for various businesses, including financial institutions.

One of the key challenges for the fintech industry in Russia is the low level of investment [16-17]. The fintech industry is based on the largest financial institutions, while there are very few independent startups, and there are no «unicorn» startups (technology startups that very quickly reach a valuation of USD 1 billion) at all. However, according to experts, the future lies with projects that will work in a fund-startup-financial/technology corporation nexus. In this case, financial monopolies may lose their influence on the market. In this case, fintech start-ups could become serious new players in the financial sector in Russia.

In the Russian Federation mass deployment of $5 \mathrm{G}$ networks, which will replace LTE (4G) technology, is due to start at the end of 2021. It was previously expected that mass deployment of the new mobile communications standard would begin in 2020, but this was postponed by a government decision due to the demand for the new technology not yet taking shape. This should only happen in the country by 2022-2023. However, start-ups in various areas of the economy, including fintech, telemedicine and cybersport, will be the drivers of the high demand for $5 \mathrm{G}$ network services. It is worth noting that the number of mobile smart device users and mobile Internet users, i.e. potential users of financial services, is already growing in Russia. According to AC\&M Consulting, there are more than 260 million mobile users in Russia. At the same time, according to experts estimates, $2 / 3$ of the country's adult population use mobile Internet, which can be explained by the relatively low cost of traffic. The mobile commerce segment is also actively growing, which in turn stimulates the development of convenient payment services and solutions related to loyalty programme. In the near term and in the context of $5 \mathrm{G}$ network deployment, these trends are unlikely to change, despite the significant costs of technological transformation incurred by operators.

A study on 6G Flagship networks has already started in Finland. According to the developers, 6G networks should appear as early as the 2030s, and standards will begin to be developed in 2025. The use of sixth-generation networks is highly likely, according to the experts, to be designed for entirely new ways of consuming information. 
Autonomous Next predicts that by 2030 , banks will be able to reduce costs by $22 \%$ with the help of artificial intelligence technologies. However, the worldwide problem remains the lack of skilled professionals.

To date, more than 30 countries around the world have already recognized the critical importance of artificial intelligence and have adopted appropriate national strategies. According to analysts' forecasts, the introduction of these technologies will ensure a doubling of the leading countries' GDP growth rates and an increase in global GDP by USD 15 trillion by 2025 .

As for the Russian Federation, its position in artificial intelligence in the global market is rather weak (market share $-0.2 \%$ ). The reasons are the low level of investment in the sector; lack of demand for artificial intelligence technologies to improve the efficiency of production of products, goods and services; lack of qualified specialists and outflow of personnel abroad. Nevertheless, there are a number of positive factors that may contribute to the development of the sector. These include a sufficiently high level of basic physics and mathematics education, a strong scientific school in the field of mathematics, etc.

The driving force behind the big data industry in Russia, as elsewhere in the world, is the leading banks (the top 10 in Russia). However, mid-tier banks are now also starting to actively integrate these technologies into their business processes. A feature of the Russian big data market is the lack of interest from foreign developers in it. According to experts, the main reason lies in the lower prices of their technological solutions compared to developed markets, which are combined with rather high requirements for the quality of support. All this allows Russian vendors to maintain their leading positions and develop technologies.

According to experts from the mobile operator MegaFon, the economic effect from the introduction of big data technologies in the next five years in Russia may reach $0.5-1.5 \%$ of GDP. This will be possible due to additional revenues generated by various companies from sales of products and services that use this technology.

In addition, big data market players intend to start making their data available to startups for free. In addition, the Internet Development Institute (IDI) and the Big Data Association (including Yandex, Mail.ru Group, MegaFon, Rostelecom, Sberbank, Gazprombank and others) have already developed a draft code of ethics for using big data. The document is expected to become the basis for industry self-regulation.

\section{Conclusion}

Actively developing financial technology, as global practice shows, is a sustainable development tool that can improve the financial industry efficiency. Despite the challenges, a technological foundation is forming for the development of new technology-based industries, including fintech. Analysis has shown that the introduction of new technologies in fintech contributes to the automation and robotization of asset allocation and private wealth management processes. At the same time, the main development will take place in the retail subsegment. By adopting fintech, companies/banks can improve their business models, reduce transaction costs, improve efficiency and create more attractive business models for customers. This will facilitate the emergence of solutions for new client categories, including those that have traditionally been considered unprofitable. Risk assessment and management approaches will also be improved. Research on the role of fintech as a transformation driver of financial markets is a promising avenue for future research and deserves further attention. 


\section{References}

1. P. Gomber, R.J. Kauffman, C. Parker, B.W. Weber. J. Manage. Inform. Syst., 35 (1), 220-265 (2018)

2. C. Haddad, L. Hornuf. Small Bus. Econ., 53 (1), 81-105 (2019)

3. J. Liu, X. Li, Sh. Wang, Technological Forecasting and Social Change, 155 (2020)

4. I. Lee, Y.J. Shin, Business Horizons, 61, 35-46 (2018)

5. M. Koenitzer, G. Bruno, P. Stein, et al, The Future of FinTech A Paradigm Shift in Small Business Finance. World Economic Forum (2015)

6. D. Yazdani, G. Weber, Global FinTech Report 2017, KPMG (2017)

7. D.W. Arner, J. Barberis, R.P. Buckley, The Finsia Journal of Applied Finance, 3, $22-$ 29 (2016)

8. S. Balan, J. Otto, E. Minasian, A. Aryal, Information Technology and Management Science, 20, 64-68 (2017), https://doi.org/10.1515/itms-2017-0011

9. N. Serbulova, et al, E3S Web Conf., 210 (2020)

10. L. Chen, China Economic Journal, 9, 225-239 (2016), https://doi.org/10.1080/17538963.2016.1215057

11. P. Gomber, J.-A. Koch, M. Siering, Journal of Business Economics, 87, 537-580 (2017), https://doi.org/10.1007/s11573-017-0852-X

12. R.R. Suryono, I. Budi, B. Purwandari, Information, 11, 1-20 (2020)

13. I.H.-Y. Chiu, Journal of Technology Law \& Policy, 21, 55-112 (2016), https://doi.org/10.3868/s050-004-015-0003-8.

14. N. Serbulova, et al, IOP Conf. Ser.: Earth Environ. Sci., 403 (2019), https://doi.org/10.1088/1755-1315/403/1/012127

15. V. Chang, P. Baudier, H. Zhang, Q. Xu, J. Zhang, M. Arami, Technological Forecasting and Social Change, 158 (2020)

16. A. Alukhanyan, K. Barmuta, O. Panfilova, D. Borisova, IOP Conference Series: Earth and Environmental Science, 403 (1), (2019), doi.org/10.1088/1755-1315/403/1/012044

17. A.S. Orobinsky, A.A. Alukhanyan, European Research Studies Journal, 21, 333-349 (2018) 